\author{
ЛюдмилА Рыжова \\ Московский городской педагогический университет (Москва, Россия)
}

\title{
Иллокутивное многообразие актов волеизъявления
}

Изучение речевых актов различной семантики, структурной сложности и целевой направленности является одной из актуальных проблем современной коммуникативно-функциональной лингвистики, где «существенно рассмотрение языка в контексте общественной практики, человеческой материальной и духовной деятельности с её субъектом и объектом, целями и мотивами, условиями и способами» (Сусов 2006: 11). Объектом данного исследования является сложный речевой акт волеизъявления, который обладает способностью определенным образом представлять общую арматуру ситуации волеизъявления, ее структурные элементы и отношения между ними. Акт волеизъявления представляет собой феномен, включающийся в структуру конкретного интерактивного пространства и подчиняющийся структуре типового интерактивного пространства, представление о котором является составной частью менталитета личности. Следует, однако, отметить, что волеизъявление является компонентом любого действия, но может, по мнению Н. Ю. Чайковской, быть осмыслено и пережито как отдельная сущность, и это относится как к семантике лексических единиц, так и к содержанию речевых актов. В качестве конститутивных признаков акта волеизъявления она выделяет наличие воли как присущей человеку способности проявлять активность, выражение воли как осуществление действия, направленного на определенный объект, перформативность как изменение действительности в результате осуществления действия, градуируемость как внутренне присущее волеизъявлению качество, наличие разнородных компонентов волеизъявления, осмысливаемых как отдельные концепты (Чайковская 2008: 7).

В силу своей направленности на осознанное воздействие говорящего на слушающего высказывание, выражающее волеизъявление, является ведущим компонентом диалогического единства, минимальный состав которого может быть ограничен двумя репликами - волеизъявительной и ответной (как вербальной, так и невербальной). Тем не менее, следует подчеркнуть, что собственно волеизъявительной реплике должна предшествовать еще одна реплика, содержащая основу, некий стимул для волеизъявления, т.е. 
волеизъявление не только предполагает ответ, но предполагает и круг исходных суждений, на основе которых возникает волеизъявление. Минимальное диалогическое единство с выражением личностных установок на волеизъявление является трехчленным, состоящим из трех реплик: исходной реплики, волеизъявительной реплики и ответной реплики. В том случае, если исходная реплика отсутствует, то акт волеизъявления опирается на ситуацию общения, на апперцепционную базу собеседников. В коммуникативном акте волеизъявления отправитель сообщения стремится вызвать в сознании (в ментальной сфере) адресата нужные или желаемые образы из действительности типового интерактивного пространства. С этой целью он включает в свое речевое произведение фонетические, графические, кинестетические знаки, устойчиво связанные с определенными значениями и их предназначением как в системе языка, так и в общем коммуникативно-социальном опыте. В силу устойчивости этой связи при смысловом восприятии речевого произведения указанные знаки вызывают в сознании адресата те образы, которые сформулировал отправитель сообщения, преследуя определенные коммуникативные цели.

Известно, что волеизъявление говорящего субъекта, проявляющееся в речевом принуждении адресата сообщения к определенному поведению, лежит в основе значения побудительности, изучению которого посвящены многочисленные труды как отечественных, так и зарубежных исследователей (см.: Беляева 1992; Корди 2009; Романов 1988; Яковлева 2005 и др.). Были определены и описаны конструктивные особенности побудительных высказываний и способы их выражения, выявлены и систематизированы различные варианты категории побуждения, изучены коммуникативно-функциональные свойства высказываний, выражающих побудительное значение. Побудительные значения образуют особый вид модальности побудительную, императивную модальность. При этом побудительная модальность рассматривается как «система побудительных грамматических значений, оформленных в каждом языке согласно его внутренним законам» (Крашенникова 1953: 457). Языковые средства репрезентации побудительного значения организованы по принципу функционально-семантического поля, ядро которого представлено императивной парадигмой, периферия средствами разных языковых уровней (Маслова 2009). Наиболее эксплицитным элементом побудительных или императивных высказываний является глагол в повелительном наклонении. В. С. Храковский и А. П. Володин разработали функциональные критерии выявления императивной парадигмы: импульс каузации, который может исходить от говорящего и слушающего, заинтересованность говорящего в исполнении каузируемого действия в интересах либо говорящего, либо слушающего, субординащия, т.е. говорящий имеет более высокий или более низкий статус. Эти критерии дали авторам возможность выделить шесть частных значений императива: приказ, прось- 
бу, инструкиию, предложение, рассматриваемых как фактитивная каузация, и разрешение, совет - как пермиссивная каузация. Использование лексико-семантического фильтра позволило выявить пожелание, а ситуационного фильтра - санкцию (Храковский, Володин 1986: 132-147).

Исследователи французского языка связывают выражение категории побудительности с функционированием особой лексико-семантической группы глаголов побуждения. Изучив семантические и прагматические свойства глаголов, обозначающих побуждение, Х. Ессен выделяет специальные побудительные глаголы, используемые для описания той или иной сферы человеческой деятельности. Например, глаголы: requerir, assigner, mander, petitionner, prohiber употребляются в правоведении; в военном деле используется глагол commander; глаголы solliciter и postuler - в административном деле; prescrire - в области медицины (Jessen 1979: 73). Д. Слакта выделяет две группы глаголов, включив в первую глаголы requerir, prier, exiger, во вторую - reclamer, solliciter, supplier (Slakta 1971: 49).

Наличие многочисленных исследований и публикаций о реализующейся в речи категории побудительности обусловлено, прежде всего, той значительной ролью, которую побудительные высказывания играют в различных сферах деятельности людей. Побуждение реализуется в определенных областях социально-практической деятельности, и социальные условия играют важную роль в определении характера побуждения. Такие факторы, как авторитарность по отношению к одному из партнеров, индивидуальная власть, социальное равноправие, предписывающие нормы общественной деятельности и определяющие взаимоотношениями между коммуникантами, необходимы для выявления типа побуждения и идентификации побудительного высказывания (Motsch 1978: 4-46).

Именно эти аспекты сыграли важную роль в изучении побудительных высказываний в прагматически ориентированных исследованиях, где побудительные высказывания рассматривались как разновидность директивных речевых актов (Вежбицка 1985; Почепцов 1981; Романов 1982; Яковлева 2005; Wunderlich 1976, Sperber, Wilson 1989 и др.). Общее коммуникативное назначение директивных речевых актов заключается в стремлении говорящего побудить партнера изменить существующее положение дел, совершив определенное действие, обозначенное в высказывании. Таким образом, побудительность в рамках прагмалингвистики рассматривается как коммуникативное значение, или иллокутивная сила, в которой находят воплощение интенциональный (целевой) и интерактивный аспекты языкового общения.

Интенциональный аспект значения высказывания, употребляемого для совершения речевого действия, связывается с понятием иллокутивной цели, иллокутивной функции и иллокутивного акта. Именно интенция (намерение), которую говорящий вкладывает при произнесении соответствующего высказывания, отличает один иллокутивный акт от другого. Иллокутивная 
цель - это установка на ответную реакцию адресата, которая прямо или косвенно сообщается ему в высказывании. Проведено большое количество исследований, в которых показано, что иллокутивные акты с одним и тем же содержанием могут иметь совершенно различные иллокутивные цели, выражать разные намерения и, реализуя в процессах взаимодействия разные иллокутивные функции, указывать на степень функционально-прагматической значимости участия коммуникантов в диалоге.

Данное положение подтверждает иллокутивную неоднозначность директивных речевых актов, зависящую от языковых средств выражения пропозиционального содержания высказывания и его директивной иллокуции. Адекватное осмысление директивных речевых актов невозможно без анализа факторов, влияющих на понимание коммуникативной интенции и определяющихся нормами общественной деятельности, социальными отношениями между коммуникантами. Такие аспекты, как авторитарность по отношению к одному из партнеров, индивидуальная власть, социальное равноправие необходимы для выявления типа волеизъявления. Среди факторов выделяют сознательность говорящего, его намерения, понимание ситуации, фоновые знания, знание партнера по коммуникации и т.п. (Gauvenet 1976; Jessen, 1979: Motsch 1978; Slakta 1971; Wunderlich 1976 и др.).

Самыми распространенными способами выражения директивной интенции и иллокутивной функции, т.е. параметрами, позволяющими оценить, какой иллокутивный акт совершается при произнесении данного предложения, признаются наклонение глагола, интонационный контур, пунктуация, ударение. К ним относится также множество так называемых перформативных глаголов, а также высказывания с перформативными глаголами.

Подробные основания для классификации директивов предлагает В. И. Карасик:

1. степень категоричности говорящего, т.е. мера психологического давления отправителя речи на адресата, выражающая волю говорящего;

2. организационная определенность желаемого действия;

3. статусное соотношение участников общения;

4. пропозициональный знак желаемого действия (утверждение либо отрицание, т.е. побуждение либо запрет);

5. первичность либо вторичность директива, т.е. выражение базового недифференцированного побуждения (непосредственный директив) либо осложненного директивного речевого действия (связанный директив);

6. эксплицитность (явное выражение) либо имплицитность (косвенность) директива;

7. внутренний оценочный знак побуждения, которое направлено на благо адресата либо не содержит такой направленности (Карасик 2002, 49-50).

Некоторые их перечисленных критериев свойственны всем речевым актам (непосредственность / опосредованность и эксплицитность / импли- 
цитность), другие - только директивам (степень категоричности, статусное соотношение коммуникантов, внутренняя оценка пропозиции) или их отдельным разновидностям (организационная определенность пропозиции, пропозициональный знак). Все директивы могут быть разделены на категоричные и некатегоричные. К первым автор относит приказы, запреты, требования, инструкции; в них выражается воля говорящего, а мнение адресата не принимается во внимание. К некатегоричным директивам, по мнению исследователя, относятся просьбы, рекомендации, советы, пожелания, извинения. В силу разных причин говорящий пытается снизить степень прямого воздействия на адресата, учитывает его позицию (Карасик 2002: 50-52).

Методологическую ценность представляют работы Е. И. Беляевой, которая выделяет следующие прагматические признаки для описания различий между основными типами директивов:

а. облигаторность выполнения действия для адресата;

б. бенефакторность действия (т.е. соответствие интересам одного из коммуникантов);

в. приоритетность положения говорящего или адресата (Беляева 1992: 16-20).

Сравнение критериев классификации директивов, предложенных В. И. Карасиком и Е. И. Беляевой, обнаруживает точки пересечения в понимании феномена директивности. Так, признак облигаторности выполнения действия близок к разделению директивов на категоричные и некатегоричные. Признак бенефакторности действия совпадает с внутренним оценочным знаком побуждения, направленным на благо адресата либо не содержащим такой направленности. Последний признак, выделенный Е. И. Беляевой, - приоритетность говорящего или адресата - тоже был рассмотрен В. И. Карасиком как статусное соотношение участников общения.

Опираясь на указанные критерии, Е. И. Беляева выделяет три основных типа директивов: прескриптивы, реквестивы, суггестивы (Беляева 1992: 16-20). Для выявления иллокутивного многообразия актов волеизъявления директивной направленности была использована данная классификация на том основании, что каждый из выделенных типов речевых актов характеризуется своим набором признаков, формирующих иллокутивное значение.

Прескриптивные директивные акты волеизъявления характеризуются приоритетностью позиции говорящего, они предписывают адресату некоторое действие, и его выполнение является обязательным для адресата. Исполнителем каузируемого действия является адресат. Он находится в неприоритетной позиции и не обладает правом решать вопрос о выполнении / невыполнении действия. Более того, невыполнение действие действия наказуемого, влечет санкции. Источником побуждения может выступать как отдельное лицо, занимающее определенную социальную позицию (позицию авторитета), так и общественный институт. Признак бенефакторности 
действия для данного типа речевых актов не является релевантным. К этому типу относятся: приказ, распоряжение, разрешение, запрещение, инструкция, предписание, заказ.

Приказ является наиболее категоричной формой директивных речевых актов, так как служебное положение говорящего обеспечивает ему право на безоговорочное побуждение адресата к действию. При этом отношение адресата к каузируемому действию ни для говорящего, ни для адресата не принимается в расчёт, а невыполнение приказа влечет за собой санкции.

Распоряжение в определенной степени приравнивается к приказу, но носит менее категоричный характер.

Разрешение. Данным речевым актом говорящий санкционирует действие, исходя из пресуппозици, что адресат желает его совершить. Таким образом, неприоритетная позиция адресата не вступает в конфликт с намерениями говорящего.

Запрещение, выступает в качестве негативной формы приказа или не разрешения. Запрещение-приказ носит категоричный характер. Не разрешение является превентивным речевым актом: наличие у адресата желания совершить некоторое действие является нежелательным для говорящего.

Требование представляет собой вид прескриптива, основанный на прагматической пресуппозиции нежелания адресата выполнить каузируемое действие. В одних случаях это нежелание обусловлено психологическим состоянием адресата, в других - непризнанием приоритетности положения говорящего. Говорящий может присвоить себе право приоритетности, действуя с «позиции силы» и принимая на себя ответственность распоряжаться действиями других людей.

Инструкция имеет целью снабдить адресата указаниями о ходе выполнения действий, способных привести к желаемому для него результату всякий раз, когда он приступает к осуществлению определенной деятельности. Обязательность выполнения инструкции определяется соображениями целесообразности, ибо невыполнение инструкции может привести к неудовлетворительным результатам, т.е. адресат будет косвенно наказан. Это особый вид категоричных прескриптивов, в которых приоритетность позиции говорящего основана на наличии у него знаний в определенной области. Инструкция базируется на прагматической пресуппозиции о том, что адресат нуждается в получении этих знаний.

Предписание является вариантом речевого акта инструкции, источником побуждения в котором служат какая-либо инстанция, законодательный орган или социальный институт. Цель таких инструкций - предписаний в том, чтобы регулировать нормы поведения лиц, принадлежащих к определенной социальной или служебной категории. Любое лицо, приняв на себя определенную позиционную (ученик, студент) или ситуационную роль (пассажир, клиент), обязан следовать нормам, предписанным в деонтических инструкциях. Несоблюдение норм наказуемо. 
Заказ выделяется в отдельный вид прескриптивного речевых актов на том основании, что его осуществление связано с конвенциональными ситуациями общения - ресторан, бар, магазин, касса, бюро обслуживания. Приоритетную позицию занимает говорящий-заказчик, что обусловлено его ситуационной ролью клиента, чьи запросы должен удовлетворять адресат. Адресат расценивает каузируемое действие как облигаторное, ибо оно входит в круг его служебных обязанностей.

Реквестивные речевые акты волеизъявления побуждают к действию, совершаемому в интересах говорящего. Позиция говорящего в этом классе директивных речевых актов не является приоритетной по сравнению с позицией адресата. Приоритетность адресата заключается в том, что является он ответственным за принятие решения, но выполнение каузируемого действия для него не обязательно. Критерий бенефакторности характеризует и говорящего и адресата. К этому типу относятся: просьба, мольба, приглашение.

Просьба рассматривается как ядерный речевой акт, поскольку остальные виды реквестивных актов имеют особенности в реализации прагматических признаков. Семантическим вариантом просьбы является запрос о разрешении. Искомое для говорящего действие адресата - дать полномочия говорящему для совершения некоторого действия, и действия говорящего по тем или иным причинам оказываются в сфере ведения другого лица, т.е. адресата.

Мольба представляет собой вариант речевого акта просьбы, но в основе мольбы лежит нежелание адресата совершить действие, к которому побуждает высказывание и наличие сильного мотива у говорящего к исполнению выраженного в акте мольбы действия. Именно этот мотив заставляет говорящего пытаться преодолеть сопротивление адресата, используя различные тактики настаивания, убеждения, аргументации.

Приглашение совмещает признаки реквестивов и суггестивов по линии бенефакторности действия: действие одновременно желаемо для говорящего и приятно или полезно для адресата. Говорящий заинтересован в принятии адресатом приглашения.

Сугzестивные речевые акты волеизъяваения характеризуются приоритетностью говорящего, необлигаторностью и бенефактивностью действия для адресата. Их иллокутивная цель состоит в побуждении адресата совершить действие, полезное для него с точки зрения говорящего. Приоритетную позицию занимает говорящий: на основе своего опыта или знания положения дел в определенной ситуации он считает себя вправе руководить действиями адресата. Однако адресат сам принимает решение о выполнении или невыполнении предлагаемого действия, которое не является обязательным для исполнения. К этому типу относятся: совет, предупреждение, предостережение, предложение. 
Cовет рассматривается как ядерный вид суггестивных речевых актов. Он обладает такими характеристиками, свойственными всем суггестивам, как необлигаторность действия, приоритетность позиции говорящего, бенефективность действия для адресата. В случае совета говорящий пытается повлиять на действия слушающего, заботясь о его интересах.

Предупреждение является косвенным побуждением, пропозициональное содержание которого указывает на существующую опасность или на возможные неблагоприятные последствия какого-либо действия для адресата.

Предостережение совмещает в себе признаки речевых актов совета и предупреждения.

Предложение представляет собой побуждение к совместному действию говорящего и единоличного или группового адресата. Совершая речевой акт предложения, говорящий не только каузирует действие других, но и обрекает себя на определенное действие. Отсюда следует, что предложение является гибридным речевым актом, совмещающим признаки директива и комиссива. Вариантом предложения является предложение собственных услуг, в этом случае исполнителем действия будет сам говорящий.

Таким образом, волеизъявление как категория, характеризующая, практически любое действие коммуникантов, обладает такими конститутивными признаками, как наличие воли т.е. присущей человеку способности проявлять активность, выражение воли через осуществление действия, в том числе вербального, направленного на определенный объект, результативность или изменение действительности в результате осуществления действия, градуируемость как внутренне присущее волеизъявлению качество, гетерогенность средств и структур волеизьявления. Существенными для иллокутивной интерпретации актов волеизъявления являются следующие признаки: мотивы побуждения, желательность / нежелательность действия, участие / неучастие в выполнении каузируемого действия, содержание действия, характер предписывающий инстанции (источника побуждения), сфера коммуникативности. Каждый тип речевого акта волеизъявления характеризуется своим набором значений и признаков, которые формируют иллокутивную направленность конкретного речевого действия в ситуации общения. В зависимости от ситуации, или, другими словами, типа прагматического контекста любые по форме высказывания получают определенную прагматическую интерпретацию и наделяются определенной прагматической силой. Так, императивное высказывание «Пойте» в прескриптивном контексте интерпретируется как приказ, в суггестивном - как совет, в реквестивном - как просьба.

\section{Библиография}

Беляева Е. И. (1992), Грамматика и прагматика побуждения: английский язык, Воронеж. Вежбицка А. (1985), Речевые акты, [в:] Новое в зарубежной лингвистике, вып. 16, Москва, c. 251-276. 
Карасик В. И. (2002), Язык соичиального статуса, 2-е изд., Москва.

Корди Е. Е. (2009), Оптатив и Императив во франиузском языке, Москва.

Крашенникова Е. А. (1953), Побудительная модальность в немеиком языке, [в:] Изв. АН СССР. ОЛЯ, т. ХІІ, вып. 5, с. 457-469.

Маслова А. Ю. (2009), Коммуникативно-семантическая категория побудительности и ее реализация в славянских языках (на материале сербского и болгарского языков в сопоставлении с русским): Дис. ... д-ра филол. наук, Санкт-Петербург.

Почепцов Г. Г. (1981), Прагматика предложения, [в:] Иванова И. П., Бурлакова В. В., Почепцов Г. Г., Теоретическая грамматика современного английского языка, Москва, c. $271-278$.

Романов А. А. (1982), Коммуникативно-прагматические и семантические свойства немеиких высказываний-просьб: Автореф. дис. ... канд. филол. наук, Калинин.

Романов А. А. (1988), Системный анализ регулятивных средств диалогического общения, Москва.

Сусов И. П. (2006), Введение в языкознание, Москва.

Храковский В. С., Володин А. П. (1986), Семантика и типология императива: Русский императив, Ленинград.

Чайковская Н. Ю. (2008) Конщептосфера «волеизъявление» в английской и русской лингвокультурах: Дис. ... канд. филол. наук, Волгоград.

Яковлева Г. Г. (2005), Директивный дискурс в диалогическом пространстве разных языков (Строевые и функциональные аспекты описания): Дис. ... Д-ра филол. наук, Тверь.

Gauvenet H. (1976), Pédagogie du discours rapporté, Paris.

Jessen H. (1978), Pragmatische Aspekte lexikalischer Semantik: Verben des Aufforderns im Französischen, Tübingen.

Motsch W. (1978), Sprache als Handlungsinstrument, Berlin, S. 11-49.

Slakta D. (1971) L'acte de demander dans les «Cahiers de Dolbances», [w:] Langue française, № 9, p. 58-73.

Sperber D., Wilson D. (1986), Relevance. Communication and cognition, Oxford.

Wunderlich D. (1976), Studien zur Sprechakttheorie, Frankfurt-am-Main.

\section{Liudmila Ryzhova}

\section{Illocutionary Variety of Acts of Will}

\section{Summary}

The object of this research is the complex speech act of will, in particular, the act included in the structure of a particular interactive space and subordinate to the structure of a standard interactive space. Constitutive signs of acts of will, that allow systematizing and classifying their illocutionary variety, come to light. Each type of speech act of will is characterized by a set of values and signs, which form an illocutionary orientation of specific speech action in a communication situation. Any form of statement receives then a certain pragmatic interpretation and they are allocated with a certain pragmatic force in each particular situation. 